\title{
RESEARCH
}

Open Access

\section{Comparison of efficiency between platelet rich plasma and corticosteroid injection therapies in patients with Carpal tunnel syndrome: a prospective randomized controlled study}

\author{
Noha Ali Hashim ${ }^{1 *}$ (D, Hala Ahmed Fathy', Marwa Mohammed Esawy² and Marwa Ahmed Shabana²
}

\begin{abstract}
Background: Carpal tunnel syndrome (CTS) is the most common upper limb entrapment neuropathy caused by compression of the median nerve as it traverses the wrist at the carpal tunnel.

Objectives: To compare the effect of single dose of platelet-rich plasma (PRP) injected locally with that of corticosteroid in patients with CTS.

Subjects and methods: A total of 60 patients with very mild to moderate unilateral CTS were recruited to the study. PRP was prepared via two centrifugation procedures. The patients were randomly divided into three groups PRP [i] group, PRP [ii] group, and a third group that received local corticosteroid injection (CS). The patients were followed up at 1.5 and 3 months by visual analog scale (VAS) for pain assessment. The severity and functional outcomes were evaluated through Boston CTS, and neurophysiological analyses were carried out.
\end{abstract}

Results: On comparing the PRP [i], PRP [ii], and CS groups, a statistically significant enhancement of all outcome variables was observed in both PRP groups at follow-up except VAS at 3 and 6 months $(P=0.073$ and $P=0.068$, respectively) in PRP [ii] group.

Conclusion: In CTS, PRP was a better treatment alternative with respect to pain and functional outcome. In addition, it was associated well with improved neurophysiological values than those observed after corticosteroid injection.

Trial registration: Zagazig University, ZU-IRB\#5014. Registered 18 December 2018, http://www.IRB_123@medicine. zu.edu.eg. ISRCTN Registry, ISRCTN16755281; 20 March 2020

Keywords: Pain assessment, Platelet-rich plasma, Corticosteroid injection, Treatment alternative, Carpal tunnel syndrome, Outcome

\footnotetext{
* Correspondence: n.hashim83@hotmail.com

${ }^{1}$ Department of Neurology, Faculty of Medicine, Zagazig University, Zagazig

University, El-Sharkia, Zagazig, Egypt

Full list of author information is available at the end of the article
}

\section{Springer Open}

(c) The Author(s). 2020 Open Access This article is licensed under a Creative Commons Attribution 4.0 International License, which permits use, sharing, adaptation, distribution and reproduction in any medium or format, as long as you give appropriate credit to the original author(s) and the source, provide a link to the Creative Commons licence, and indicate if changes were made. The images or other third party material in this article are included in the article's Creative Commons licence, unless indicated otherwise in a credit line to the material. If material is not included in the article's Creative Commons licence and your intended use is not permitted by statutory regulation or exceeds the permitted use, you will need to obtain permission directly from the copyright holder. To view a copy of this licence, visit http://creativecommons.org/licenses/by/4.0/. 


\section{Introduction}

Carpal tunnel syndrome (CTS) is a very well-known and frequent form of nerve entrapment $[1,2]$. CTS is a neuropathy caused by the entrapment of the median nerve at the wrist in a tunnel, delimitated by the carpal bones and by the transverse carpal ligament [3], and accounts for $90 \%$ of all entrapment neuropathies [4]. High pressure on the median nerve produces gradual ischemia of the nerve in addition to inflammation of the intra-carpal tendon which produces intra-carpal swelling causing increased compression of median nerve [5].

While a variety of surgical and nonsurgical methods are available to treat CTS, majority of patients seek conservative treatment before going for surgery. However, conservative treatment options such as magnet therapy, ultrasound, yoga, hand splints, or chiropractic treatment do not show any significant improvement in symptoms when compared to a placebo or control [6]. The use of steroid injections has been under significant scrutiny in research focusing on the conservative treatment of CTS [7]. A systematic review by Marshall and colleagues reported that steroid injections given to patients with clinical CTS elicited a greater clinical improvement in symptoms 1 month after the injection compared to a placebo, whereas corticosteroid injections alone have not demonstrated a long-term effect on pain or function [8]. There is a lack of consistency in treatment success reported in the literature, thus, it is important to investigate new nonsurgical techniques for the treatment and recovery of patients with CTS.

Local injection of platelet-rich plasma (PRP) has recently gained attention as a potential treatment for CTS. For PRP injections, the patient's blood is collected and centrifuged to achieve a very high concentration of platelets, then, this plasma is injected into the entrapment area [9]. This injection saturates the damaged tissue with supra physiological levels of growth factors to promote wound healing, angiogenesis, and improve axonal regeneration. The high concentration of platelets in PRP than in whole blood was shown to have a greater effect on the repair process [10].

The platelets concentration in the therapeutic PRP should be 4 to 6 times greater than that of whole blood. The concentrations less than this may be ineffective or contrarily lead to suppression of the healing process [11].

Marx and colleagues stated the importance of doublecentrifugation technique to truly concentrate platelets from autologous blood [12]. On the other hand, Anitua [13] used a single-spin technique and demonstrated improvement and acceleration in bone regeneration as well as more rapid and predictable soft tissue healing in sites designated for implants that were treated with PRP despite the number of platelets. Likewise, other authors have also reported obtaining platelet concentrations of $356 \%$ through the single spin technique [14].
This study aimed to compare the effects of a single PRP injection prepared using either the single or double centrifugation protocol versus corticosteroid injection on pain relief and functional outcome in the CTS treatment.

\section{Methods}

This was a prospective, blind randomized, comparative study on 60 patients with CTS referred to the Neurology Department, Zagazig University Hospitals, Egypt, between January and June 2019. Inclusion criteria were patients > 18 years suffering from mild to moderate unilateral CTS with the participant ready to have either a corticosteroid or PRP injection.

The following exclusion criteria were severe or bilateral CTS, previous steroid injection for CTS, use of corticosteroid or anticlotting drugs, wrist surgery, polyneuropathy, cervical spondylosis, brachial plexopathy, thoracic outlet syndrome, thrombocytopenia, platelet dysfunction, diabetes mellitus, uncontrolled hypothyroidism, renal or hepatic disease, pregnancy, rheumatologic disorders, psychiatric disorders, or serious mental stress.

The medical history of all 60 patient participants of our study were taken, physical examination through Tinel's sign and Phalen's test and pain assessment by visual analog scale (VAS) reported by the patient, ranging from zero (no pain) to ten (maximum pain) [15]. The diagnosis was confirmed by the electrophysiological study as per the American Association of Electrodiagnostic Medicine protocol [16], by an EMG machine (Nemus, Biomedica, Model number 00655, Galileo NT software version 3.71/00, Italy).

According to the neurophysiological grading for CTS, patients were classified as follows: very mild (grade 1), CTS confirmed only with most sensitive tests (inching, combined sensory index, palm/wrist median/ulnar comparison); mild (grade 2), only orthodromic sensory nerve conduction velocity slow at $<40 \mathrm{~m} / \mathrm{s}$ with normal terminal motor latency; moderate (grade 3), motor terminal latency $>4.5 \mathrm{~ms}$ and $<6.5 \mathrm{~ms}$ with preserved sensory nerve action potential of the index finger [17]. The nerve conduction study was repeated twice for all patients at 1.5 months and at 3 months after injection.

The patients were randomly categorized in 1:1:1 ratio into three groups PRP [i] group, PRP [ii] group, and a third group (CS) that received local corticosteroid injection. Randomization was done by an independent researcher via computer-generated randomization of study numbers on excel $^{\circ} 2007$ (Microsoft Co., Redmond, WA, USA). The clinical examination and nerve conduction study were done by a researcher who was blind to the type of the given injection.

Three peripheral venous blood samples were collected aseptically from each subject from the PRP groups into 
tubes with sodium citrate as an anticoagulant $\left(\mathrm{BD}^{\circ}\right.$ vacutainer). Whole blood platelet counts were determined using the cell counter (Sysmex Kx-21, Japan).

In order to prepare PRP, the laboratory bench-top centrifuge (NÜVE: NF 400) was used at two different centrifugation times and rotation per minutes (rpm). PRP [i] was separated by a single centrifugation step at $1600 \mathrm{rpm}$ for $8 \mathrm{~min}$, and then the plasma above the erythrocyte layer was collected immediately [18]. PRP [ii] was separated by two steps of centrifugation procedures. The samples were centrifuged first at $1200 \mathrm{rpm}$ for $10 \mathrm{~min}$; the plasma was separated from packed red blood cells and re-centrifuged at $3700 \mathrm{rpm}$ for $10 \mathrm{~min}$. The upper two-third volume of plasma, which is poor in platelets, was removed; the platelet pellet was suspended in a minimum quantity of plasma by gently shaking the tube [19], and the PRP was activated endogenously the soft tissue collagen [20]. The remnant PRP was counted using the cell counter (Sysmex Kx-21, Japan). The mean of platelet counts after each method was calculated, and the enrichment percentage was determined as follows: platelet enrichment $=$ (platelet count PRP - platelet count whole blood)/platelet count whole blood $\times 100$.

The hand of the patient was supinated in a neutral or slightly extended position for better exposure of the carpal tunnel. Lidocaine $(1 \% ; 0.5 \mathrm{ml})$ was injected using a 25 -gauge needle at the distal wrist crease on the ulnar side to the palmaris longus tendon (which can be located by having the patient pinch the thumb and fifth fingers together while slightly flexing the wrist), and the needle was inserted nearly to the ulnar at the midline. The needle was angled downward at $45^{\circ}$ toward the tip of the middle finger and advanced $1-2 \mathrm{~cm}$ as it traverses the flexor retinaculum. With the needle at the previous site, the syringe was changed, and $1 \mathrm{ml}$ of the prepared PRP [i] and [ii] was injected in the first and second group, respectively.

Using the same procedure, a single injection of methylprednisolone acetate at $40 \mathrm{mg} / 1 \mathrm{~mL}$ was injected in the third group. Patients were observed for $30 \mathrm{~min}$ after injection and were advised to rest the injected arm for $48 \mathrm{~h}$.

The severity of pain was evaluated at 1.5 and 3 months after injection as VAS range from $0-10$. The severity and functional outcome were evaluated using the Boston Carpal Tunnel Syndrome Questionnaire (BCTSQ) [21]. BCTSQ evaluates two domains of CTS: (a) symptoms severity using a scale of 11 items (pain, paresthesia, numbness, weakness, and nocturnal symptoms) and (b) functional assessment using a scale of eight items (writing, buttoning, holding, gripping, bathing, and dressing). The questionnaire was in a multiple choice format with scores ranging from one (mildest) to five (most severe). Each score was calculated as the mean of the response of the individual items.

\section{Statistical analysis}

Shapiro-Wilk test was used to verify the normality of distribution of continuous variables. Continuous variables are presented as mean $\pm \mathrm{SD}$. Categorical variables are summarized as absolute (numbers) and relative frequencies (percentage). Comparisons between quantitative variables were done using one way ANOVA and least significant difference (LSD) test or Student's $t$ test. For comparing categorical data, chi-squared $\left(\mathrm{x}^{2}\right)$ test was performed. Statistical analysis was carried out using SPSS $^{\oplus}$ statistical software version 22 [22]. $P$ value $<0.05$ was considered as statistically significant.

\section{Results}

The demographic profile and clinical data of CTS patients are presented in Table 1. A total of 60 subjects were enrolled in this clinical trial, including 20 patients ( 3 males and 17 females; mean age $48.8 \pm 7.45$ years) in PRP [i] group, 20 patients (2 males and 18 females; mean age $48.8 \pm 6.62$ years) in PRP [ii] group, and 20 patients ( 2 males and 18 females) mean age $49.15 \pm 6.06$ years in the CS group. The patients' characteristics were matched with each other with no significant differences between the groups $(P>0.05)$. Only the platelet count in PRP [ii] was significantly higher than that in PRP [i] $(P<0.0001)$. The enrichment percentages attained by both methods were $112.15 \%$ and $226.4 \%$, respectively.

On comparing the pre-injection status, PRP [i] group showed a significant improvement in all outcome variables detected at 1.5 and 3 months of follow-up $(P<$ 0.03 ), while on comparing follow-up values at 1.5 and 3 months, a statistically significant improvement in all outcome variables was observed in the PRP [i] $(P<0.01)$ (except BCTQf $P=0.29$ and SPL $P=0.07$ ).

On considering PRP [ii], a significant improvement in all outcome variables was observed at all times of follow-up $(P<0.03)$. On comparing the results of 1.5 and 3 months of follow-up, a statistically significant improvement in VAS and DML $(P=0.004,0.001$, respectively) was detected, and no statistically significant difference was observed in BCTQs, BCTQf, and SPL $(P=0.07,0.15,0.23$, respectively) (Fig. 1$)$.

In the CS group, a significant improvement only in BCTQf was detected at 1.5 months of follow-up compared to the pre-injection status $(P=0.02)$, and no significant difference in VAS, BCTQs, DML, and SPL were detected $(P=0.16,0.2,0.58$, and 0.23 , respectively). A statistically significant improvement in all outcome variables was detected in the CS group when the value of 3 months was compared to that of the pre-injection stage $(P<0.003)$ (except SPL $P=0.2)$. On comparing follow- 
Table 1 Demographic and clinical characteristics of the study subjects

\begin{tabular}{|c|c|c|c|c|}
\hline Parameter & PRP [i] group (number = 20) & PRP [ii] group (number = 20) & CS group (number = 20) & $P$ \\
\hline Age (year) & $48.8 \pm 7.45$ & $48.8 \pm 6.62$ & $49.15 \pm 6.06$ & 0.975 \\
\hline \multicolumn{5}{|l|}{ Gender } \\
\hline Male & $3(32 \%)$ & $2(28 \%)$ & $2(28 \%)$ & \multirow[t]{2}{*}{0.676} \\
\hline Female & $17(68 \%)$ & $18(72 \%)$ & $18(72 \%)$ & \\
\hline BMI & $29.07 \pm 1.4$ & $28.8 \pm 2.22$ & $28.47 \pm 1.81$ & 0.578 \\
\hline History of diabetes & $3(15 \%)$ & $4(20 \%)$ & $4(20 \%)$ & 0.895 \\
\hline History of hypertension & $6(30 \%)$ & $4(20 \%)$ & $6(30 \%)$ & 0.711 \\
\hline Duration of disease (month) & $24.1 \pm 7.05$ & $24.34 \pm 5.88$ & $23.3 \pm 7.26$ & 0.908 \\
\hline \multicolumn{5}{|l|}{ Lesion site } \\
\hline Right & $13(65 \%)$ & $14(70 \%)$ & $14(70 \%)$ & \multirow[t]{2}{*}{0.926} \\
\hline Left & $7(35 \%)$ & $6(30 \%)$ & $6(30 \%)$ & \\
\hline \multicolumn{5}{|l|}{ Grade } \\
\hline Very mild & $3(15 \%)$ & $3(15 \%)$ & $2(10 \%)$ & \multirow[t]{3}{*}{0.390} \\
\hline Mild & $4(20 \%)$ & $2(10 \%)$ & $4(20 \%)$ & \\
\hline Moderate & $13(65 \%)$ & $15(75 \%)$ & $14(70 \%)$ & \\
\hline VAS & $7.65 \pm 1.35$ & $6.37 \pm 2.01$ & $6.7 \pm 2$ & 0.113 \\
\hline BCTQs & $25.45 \pm 7.1$ & $25.8 \pm 6.16$ & $25.55 \pm 7.65$ & 0.979 \\
\hline BCTQf & $17.05 \pm 6.14$ & $16.68 \pm 6.12$ & $16.5 \pm 4.77$ & 0.904 \\
\hline $\mathrm{DML}(\mathrm{ms})$ & $5 \pm 1.12$ & $4.79 \pm 1.4$ & $5.05 \pm 1.19$ & 0.794 \\
\hline SPL (ms) & $4.99 \pm 1.04$ & $4.6 \pm 0.61$ & $4.58 \pm 0.49$ & 0.156 \\
\hline Platelet whole blood $\left(10^{3} / \mu \mathrm{L}\right)$ & $194.3 \pm 45.12$ & $204.1 \pm 48.34$ & - & 0.051 \\
\hline Platelet PRP $\left(10^{3} / \mu \mathrm{L}\right)$ & $412.1 \pm 9.07$ & $666.3 \pm 101.4$ & - & $<0.0001^{*}$ \\
\hline
\end{tabular}

Data are presented as number and percentage or mean \pm standard deviation PRP platelet-rich plasma, CS Corticosteroid, BMI body mass index, VAS visual analog scale, BCTQ Boston Carpal Tunnel Syndrome Questionnaire (s: severity and f: function), DML distal motor latency, SPL sensory peak latency *Significant

up values at 1.5 and 3 months, CS group showed a statistically significant improvement in VAS, BCTQf, and DML $(P=0.003,0.008$, and 0.002 , respectively), while no significant difference was detected in BCTQs and SPL $(P=0.08,0.23$, respectively) (Fig. 1$)$.

When the outcome variables of the two groups of PRP were compared, there was no significant difference in their enhancement at all follow-up time. Statistically significant enhancement in all outcome variables was observed when PRP [i] and CS groups were compared at all follow-up times. Likewise, a statistically significant enhancement in all outcome variables was observed when the PRP [ii] and CS groups were compared at all follow-up times except VAS at 1.5 and 3 months $(P=$ 0.073 and $P=0.068$, respectively) (Table 2 ).

\section{Discussion}

Currently, no clear gold-standard treatment is available for patients with CTS, despite of the high incidence of CTS and multitude of available treatment options. Successful, less invasive treatment modalities are essential, particularly for the aging population. The purpose of this study was to compare three local treatment options, PRP prepared by two different methods and corticosteroid, for the treatment of CTS.

Our results showed significant improvement in all the parameters in both PRP groups at 1.5 and 3 months of follow-up compared with the baseline.

In the CS group, there was a significant improvement only in BCTQf at 1.5 months follow-up, although after 3 months, a significant improvement in all parameters except SPL of the median nerve was observed.

Compared with the CS injection group, the outcomes including BCTQs, BCTQf, DML, and SPL of the median nerve improved significantly better in both PRP groups at 1.5 and 3 months after treatment. In terms of severity of pain assessed by VAS, only PRP [i] showed significant improvement than CS injection group.

This is in accordance with the reports of $\mathrm{Wu}$ and colleagues and Uzun and colleagues who documented that PRP effectively relieves pain and improves disability in the patients with CTS in follow-up for 6 months [23, 24]. Likewise, Malahias and colleagues showed very encouraging outcomes regarding the use of PRP for CTS treatment [25]. 


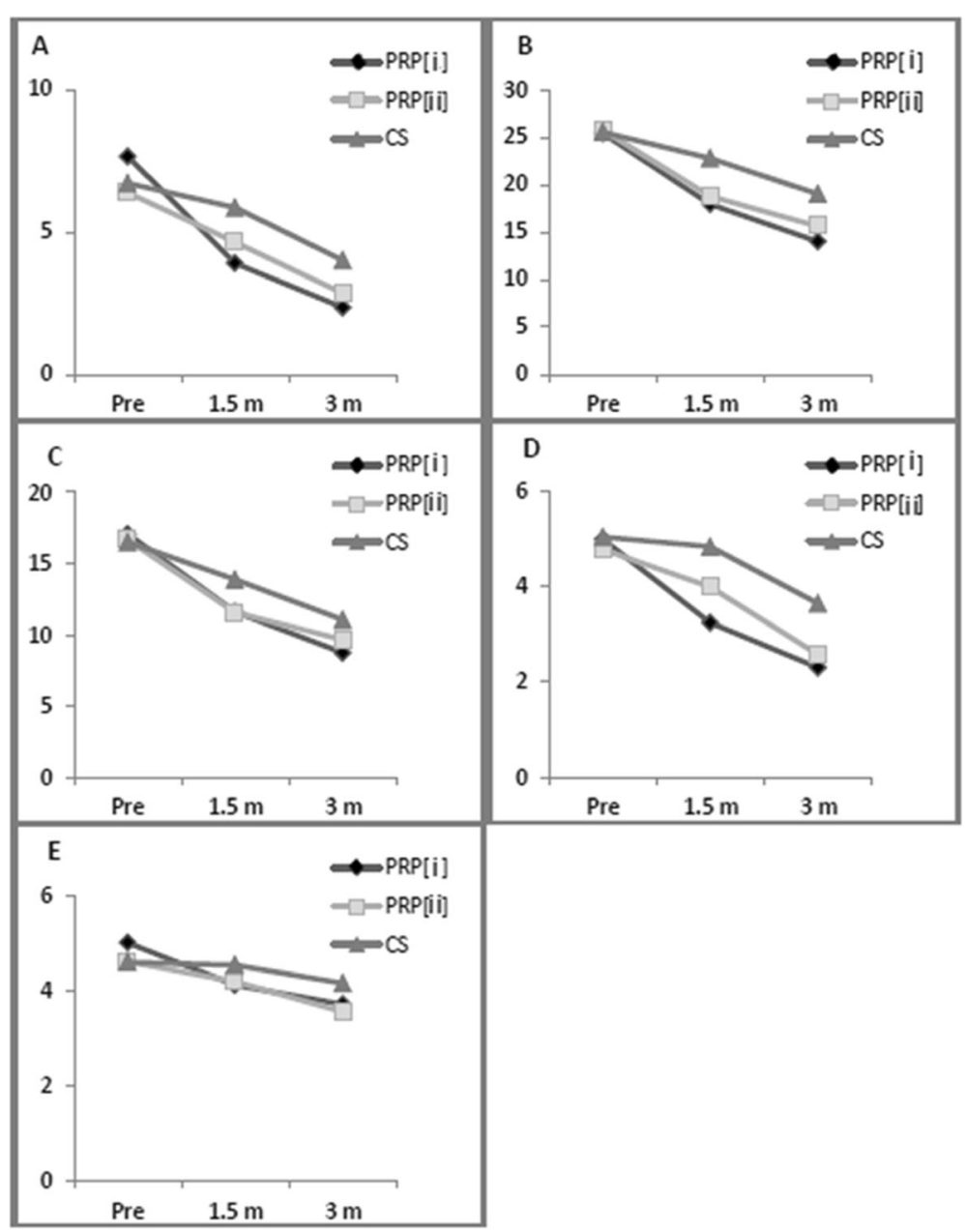

Fig. 1 Mean changes in outcome variables at pre-injection and 1.5 and 3 months follow-up. a VAS, visual analog scale; b BCTQs, Boston Carpal Tunnel Syndrome Questionnaire severity; c BCTQf, Boston Carpal Tunnel Syndrome Questionnaire function; d DML, distal motor latency; and e SPL, sensory peak latency. On comparing the pre-injection status, PRP [i] and PRP [ii] groups showed significant improvement in all outcome variables detected at 1.5 and 3 months of follow-up. In the CS group, a significant improvement only in BCTQf was detected at 1.5 months of follow up compared to the pre-injection status $(P=0.02)$. PRP, platelet rich plasma; CS, corticosteroid

In Egyptian study, single local injection of the PRP prepared with centrifugation first at speed of $3000 \mathrm{rpm}$ for $3 \mathrm{~min}$ and second at speed of $4000 \mathrm{rpm}$ for $15 \mathrm{~min}$ seemed to be superior to steroid in the treatment of CTS, showing more improvement clinically as regard the pain and function and electrophysiological outcome [26]. PRP could limit nerve damage in carpal tunnel model in a 12-week follow-up as demonstrated by a significant improvement in patients' electrophysiology [27]. However, Raeissadat and colleagues conducted a randomized controlled study on 40 females with mild CTS and showed that there was no significant benefit of the PRP injection in comparison to the conservative treatment with wrist splints in a 10-week follow-up [9]. However, the conclusion of this study may be irresolute because such differences may arise due to the use of different devices to separate PRP from whole blood. Different PRP-separation devices result in differences in platelet concentrations, $\mathrm{pH}$ [28], and in leukocyte and growthfactor concentrations [29].

The clinical benefit of PRP in peripheral neuropathy is an interesting field of research. In a case report, Sanchez and colleagues stated that proximal and distal ultrasoundguided PRP injections given intraneurally and perineurally in a common peroneal nerve exhibited a significant functional recovery assessed by electromyographic signs of reinnervation for both [30]. Additionally, perineural PRP injections in tibial and ulnar nerves have shown sensory improvement in peripheral neuropathy in leprosy [31]. PRP injection showed improvement in facial nerve regeneration in the rat model, Farrag and colleagues reported that PRP may enhance the myelin thickness and increase the axon counts when an injured nerve is sutured and assisted with PRP [32]. De Cortazar and colleagues concluded that PRP enhance the healing process of radial 
Table 2 Outcome variables at 1.5 and 3 months of follow-up in the PRP and control groups

\begin{tabular}{|c|c|c|c|c|c|c|}
\hline Parameter & PRP [i] (number = 20) & PRP [ii] (number = 20) & CS group (number $=20$ ) & $P(1)$ & $P(2)$ & $P(3)$ \\
\hline \multicolumn{7}{|l|}{ VAS } \\
\hline $1.5 \mathrm{~m}$ & $3.9 \pm 1.97$ & $4.63 \pm 1.67$ & $5.85 \pm 2.01$ & 0.163 & $0.002^{*}$ & 0.073 \\
\hline $3 \mathrm{~m}$ & $2.35 \pm 1.87$ & $2.84 \pm 1.83$ & $4 \pm 1.65$ & 0.292 & $0.005^{*}$ & 0.068 \\
\hline \multicolumn{7}{|l|}{ BCTQs } \\
\hline $1.5 \mathrm{~m}$ & $17.95 \pm 4.06$ & $18.79 \pm 4.25$ & $22.8 \pm 6.65$ & 0.785 & $0.005^{*}$ & $0.01 *$ \\
\hline $3 m$ & $14 \pm 2.6$ & $15.63 \pm 3.7$ & $19 \pm 5.77$ & 0.302 & $<0.0001^{*}$ & $0.01 *$ \\
\hline \multicolumn{7}{|l|}{ BCTQf } \\
\hline $1.5 \mathrm{~m}$ & $11.6 \pm 3.14$ & $11.58 \pm 2.8$ & $13.89 \pm .96$ & 0.829 & $0.019^{*}$ & $0.011 *$ \\
\hline $3 \mathrm{~m}$ & $8.75 \pm 1.02$ & $9.63 \pm 1.42$ & $11.06 \pm 2.11$ & 0.116 & $<0.0001^{*}$ & $0.004^{*}$ \\
\hline \multicolumn{7}{|l|}{$\mathrm{DML}(\mathrm{ms})$} \\
\hline $1.5 \mathrm{~m}$ & $3.25 \pm 0.79$ & $4 \pm 1.29$ & $4.85 \pm 1.27$ & 0.081 & $<0.0001^{*}$ & $0.012^{*}$ \\
\hline $3 \mathrm{~m}$ & $2.3 \pm 0.86$ & $2.58 \pm 1.17$ & $3.65 \pm 0.93$ & 0.532 & $<0.0001^{*}$ & $0.001 *$ \\
\hline \multicolumn{7}{|l|}{ SPL (ms) } \\
\hline $1.5 \mathrm{~m}$ & $4.11 \pm 0.82$ & $4.18 \pm 0.57$ & $4.53 \pm 0.54$ & 0.43 & $0.03^{*}$ & $0.02^{*}$ \\
\hline $3 \mathrm{~m}$ & $3.7 \pm 0.38$ & $3.55 \pm 0.31$ & $4.14 \pm 0.44$ & 0.07 & $0.001^{*}$ & $<0.0001^{*}$ \\
\hline
\end{tabular}

Data are presented as mean \pm standard deviation

$P$ (1) PRP[i] versus PRP [ii], P (2) PRP [i] versus CS, P (3) PRP [ii] versus CS, PRP platelet-rich plasma, CS corticosteroid, VAS visual analog scale, BCTQ Boston Carpal Tunnel Syndrome Questionnaire (s: severity and f: function), DML distal motor latency, SPL sensory peak latency

*Significant

nerve palsy [33]. Furthermore, Sariguney and colleagues showed a better functional outcome of peroneal nerve palsy with drop foot associated with improvement in the myelin thickness and the onset of latency [34]. PRP has also been applied to reduce neuropathic pain caused by arthroplasty, trans-gluteal decompression of pudendal nerve [35], and on the surgical site following tonsillectomy [36].

PRP exerts multiple biological activities including modulatory effects on inflammation and angiogenesis which may lead to relief from pain [37]. PRP consists of a pool of growth factors including platelets derived growth factors (PDGF $\alpha \alpha$, PDGF $\beta$, and PDGF $\alpha \beta$ ), epidermal growth factor, basic fibroblast growth factor, and transforming growth factor beta (TGFB). These factors singly or in combination have been shown to exert an antiapoptotic and neuroprotective effect on mesenchymal stem cells (MSCs), neurons, SCs, and human neural stem cells $[38,39]$. Additionally, these growth factors result in enhanced stimulation in type III collagen production, a relatively lower stimulation of type I collagen production and increase in alpha 2 than alpha 1 collagen production in cells of flexor retinaculum; these alternations lead to pathological changes in CTS [40].

PRP enhances the regenerating nerve fibers and improves neuromuscular activities [41]. The promotion of axon regeneration may result in the secretion of nerve growth factor (NGF), brain-derived neurotrophic factor (BDNF) from MSCs, and their promotion of angiogenesis $[42,43]$ and improvement in nerve regeneration
[44]. The application of PRP increases the number of nerve fibers after peripheral nerve re-anastomosis and can produce a neurotrophic effect, stimulating the proliferation of Schwann cells and myelination, which are important components during peripheral nerve repair [45].

Our study revealed no significant difference in all outcome variables at all follow-up time between the two PRP groups, although significantly higher platelet enrichment in PRP [ii] was observed. Dugrillon and colleagues reported that the platelet count is not always proportional to the quantity of growth factors [46]. Bausset and colleagues reported that vascular endothelial growth factor (VEGF) levels did not correlate with variation in platelet count [47]. Similarly, Weibrich and colleagues observed that platelet count may not be an appropriate indicator to predict the biological activity of platelets [48].

There are several important factors that should be considered with regard to the choice of the method of the PRP preparation in addition to the number of centrifugation cycles. The force of gravity used in the centrifugation process is one. However, the platelets may get prematurely activate on increasing the gravity used for the centrifugation [46], by excessive pipetting [49] or by the type of anticoagulant used during the preparation of PRP [50].

Premature activation of platelets may lead to an early release of growth factors, causing them to move to the top of the tube during centrifugation. Thus, the resultant PRP would be poor in growth factors [51]. The levels of 
growth factors in the PRP samples of the present study were not measured; hence, further studies are required to confirm this hypothesis.

In summary, the quality of PRP is more important than the number of concentrated platelets. Further studies are recommended to assess the quality and the clinical impact of PRP, as there is high inter-individual variability in cellular production and storage of cytokines [47]. The positive effect of PRP and the significant clinical outcome of this study in parallel with the other results described here support the therapeutic use of PRP as versatile and safe biological products in the treatment of early mild to moderate CTS and worth for further investigation in other peripheral neuropathies.

\section{Acknowledgements}

The authors would like to appreciate all participants as well as the hospital staff who contributed to the study.

\begin{abstract}
Authors' contributions
Hashim NA and Fathy HA collected the patients, gathered clinical data, wrote the manuscript, designed the study, and had done the statistical analysis. Esawy MM and Shabana MA had done the laboratory work of the study and improvised the manuscript for intellectual content. All authors were involved in drafting the article or revising it critically for important intellectual content, and all authors read and approved the final version to be published.
\end{abstract}

\section{Funding}

This study was not supported by any source of finding.

\section{Availability of data and materials}

Data and materials supporting the results of this article are included within the article (and its additional file(s)).

\section{Competing interest}

The authors declared that they have no conflicts of interest with respect to the authorship and/or publication of this article.

\section{Ethics approval and consent to participate}

The study was approved from the Institutional Ethics Committee of the Faculty of Medicine, Zagazig University (ZU-IRB \#5014/18-12-2018). Written informed consent was obtained from all study participants after explaining the details and benefits as well as risks to them. Surrogate consent from the patient's legal guardian or designated health proxy was permitted in cases where the patient did not have decision-making capacity.

\section{Consent for publication}

Not applicable

\section{Author details}

'Department of Neurology, Faculty of Medicine, Zagazig University, Zagazig University, El-Sharkia, Zagazig, Egypt. ${ }^{2}$ Department of clinical pathology, Faculty of Medicine, Zagazig University, El-Sharkia, Zagazig, Egypt.

Received: 5 March 2020 Accepted: 14 May 2020

Published online: 19 June 2020

\section{References}

1. American Academy of Orthopaedic Surgeons Work Group Panel. Clinical guidelines on diagnosis of carpal tunnel syndrome, 2007.

2. Pfeffer GB, Gelberman RH, Boyes JH, Rydevik B. The history of carpal tunnel syndrome. J Hand Surg (Br). 1988;13(1):28-34.

3. Alfonso C, Jann S, Massa R, Torreggiani A. Diagnosis, treatment and followup of the carpal tunnel syndrome: a review. Neurol Sci. 2010;31(3):243-52.

4. Aroori S, Spence RA. Carpal tunnel syndrome. Ulster Medical J. 2008;77(1):6-17.
5. Karadas O, Tok F, Ulaş UH, Odabaşi Z. The effectiveness of triamcinolone acetonide vs. procaine hydrochloride injection in the management of carpal tunnel syndrome: a double-blind randomized clinical trial. Am J Phys Med Rehabil. 2011:90:287-92.

6. O'Connor D, Marshall S, Massy-Westropp N. Non-surgical treatment (other than steroid injection) for carpal tunnel syndrome. Cochrane Database Syst Rev. 2003;1:CD003219.

7. Prime MS, Palmer J, Khan WS, Goddard NJ. Is there light at the end of the tunnel? Controversies in the diagnosis and management of carpal tunnel syndrome. Hand (N Y). 2010;5(4):354-60.

8. Marshall S, Tardif G, Ashworth N. Local corticosteroid injection for carpal tunnel syndrome. Cochrane Database Syst Rev. 2007;2:CD001554.

9. Raeissadat AS, Karimzadeh A, Hashemi M, Bagherzadeh L. Safety and efficacy of platelet-rich plasma in treatment of carpal tunnel syndrome; a randomized controlled trial. BMC Musculoskelet Disord. 2018;19:49.

10. Sampson S, Gerhardt M, Mandelbaum B. Platelet rich plasma injection grafts for musculoskeletal injuries: a review. Curr Rev Musculoskelet Med. 2008;1: 165-74.

11. Crane D, Everts PAM. Platelet rich plasma (PRP) matrix grafts. Pract Pain Manag. 2008;8:1-10.

12. Marx RE, Carlson ER, Eichstaedt RM, Schimmele SR, Strauss JE, Georgeff KR. Platelet-rich plasma: growth factor enhancement for bone grafts. Oral Surg Oral Med Oral Pathol Oral Radiol. 1998;85:638-46.

13. Anitua E. Plasma rich in growth factors: preliminary results of use in the preparation of sites for implants. Int J Oral Maxillofac Implants. 1999;14:529-35.

14. Eby EW. Platelet-rich plasma: harvesting with a single-spin centrifuge. J Oral Implantol. 2002;28:297-301.

15. McCormack HM, Horne DJ, Sheather S. Clinical applications of visual analogue scales: a critical review. Psychol Med. 1988;18:1007-19.

16. Jablecki CK, Andary MT, So YT, Wilkins DE, Williams FH. Literature review of the usefulness of nerve conduction studies and electromyography for the evaluation of patients with carpal tunnel syndrome. Muscle Nerve. 1993;16: 1392-414.

17. Bland JD. A neurophysiological grading scale for carpal tunnel syndrome. Muscle Nerve. 2000;23(8):1280-3.

18. Anitua E, Aguirre JJ, Algorta J, Ayerdi E, Cabezas Al, Orive G, et al. Effectiveness of autologous preparation rich in growth factors for the treatment of chronic cutaneous ulcers. J Biomed Mater Res B Appl Biomater. 2008;84(2):415-21.

19. Araki J, Jona $M$, Eto $H$, Aoi $N$, Kato $H$, Suga $H$, et al. Optimized preparation method of platelet-concentrated plasma and noncoagulating plateletderived factor concentrates: maximization of platelet concentration and removal of fibrinogen. Tissue Eng Part C Methods. 2012;18(3):176-85.

20. Dhurat $R$, Sukesh M. Principles and methods of preparation of platelet-rich plasma: a review and author's perspective. J Cutan Aesthet Surg. 2014;7(4): 189-97.

21. Levine DW, Simmons BP, Koris MJ, Daltroy LH, Hohl GG, Fossel AH, et al. A self-administered questionnaire for the assessment of severity of symptoms and functional status in carpal tunnel syndrome. J Bone Joint Surg Am.1993; 75:1585-92.

22. Levesque R. SPSS programming and data management: a guide for SPSS and SAS users (4th ed.). Chicago, 3. Illinois. 2007: SPSS Inc. ISBN 978-156827-390-7.

23. Wu YT, Ho TY, Chou YC, Ke MJ, Li TY, Tsai CK, et al. Six-month efficacy of perineural dextrose for carpal tunnel syndrome: a prospective, randomized, double-blind, controlled trial. Mayo Clin Proc. 2017;92(8):1179-89.

24. Uzun H, Bitik O, Uzun Ö, Ersoy US, Aktaş E. Platelet-rich plasma versus corticosteroid injections for carpal tunnel syndrome. J Plast Surg Hand Surg. 2017;51(5):301-5.

25. Malahias MA, Nikolaou VS, Johnson EO, Kaseta MK, Kazas ST, Babis GC. Platelet-rich plasma ultrasound-guided injection in the treatment of carpal tunnel syndrome: a placebo-controlled clinical study. J Tissue Eng Regen Med. 2018;12(3):e1480-8.

26. Atwa ET, Esh AM, Abd El Al IT, Awad YM. Platelet-rich plasma versus corticosteroid injections for carpal tunnel syndrome: clinical and electrophysiological study. The Egyptian Rheumatologist. 2019;41(3):237-41.

27. Park GY, Kwon DR. Platelet-rich plasma limits the nerve injury caused by 10\% dextrose in the rabbit median nerve. Muscle Nerve. 2014;49(1):56-60.

28. Fitzpatrick J, Bulsara MK, McCrory PR, Richardson MD, Zheng MH. Analysis of platelet-rich plasma extraction: variations in platelet and blood components between 4 common commercial kits. Orthop J Sports Med. 2017;5:1. 
29. Perut F, Filardo G, Mariani E, Cenacchi A, Pratelli L, Devescovi V, et al. Preparation method and growth factor content of platelet concentrate influence the osteogenic differentiation of bone marrow stromal cells. Cytotherapy. 2013;15(7):830-9.

30. Sanchez M, Yoshioka T, Ortega M, Delgado D, Anitua E. Ultrasound-guided platelet-rich plasma injections for the treatment of common peroneal nerve palsy associated with multiple ligament injuries of the knee. Knee Surg Sports Traumatol Arthrosc. 2014;22:1084-9.

31. Anjayani S, Wirohadidjojo YW, Adam AM, Suwandi D, Seweng A, Amiruddin MD. Sensory improvement of leprosy peripheral neuropathy in patients treated with perineural injection of platelet-rich plasma. Int J Dermatol. 2014;53:109-13.

32. Farrag TY, Lehar M, Verhaegen P, Carson KA, Byrne PJ. Effect of platelet rich plasma and fibrin sealant on facial nerve regeneration in a rat model. Laryngoscope. 2007;117:157-65.

33. De Cortázar UG, Padilla S, Lobato E, Delgado D, Sánchez M. Intraneura Platelet-rich plasma injections for the treatment of radial nerve section: a case report. J Clin Med. 2018;7(2):13.

34. Sariguney Y, Yavuzer R, Elmas C, Yenicesu I, Bolay H, Atabay K. Effect of platelet-rich plasma on peripheral nerve regeneration. J Reconstr Microsurg. 2008;24:159-67.

35. Hibner M, Castellanos ME, Drachman D, Balducci J. Repeat operation for treatment of persistent pudendal nerve entrapment after pudendal neurolysis. J Minim Invasive Gynecol. 2012;19:325-30.

36. Semenov FV, lakobashvili I. Usage of platelet-enriched plasma as hemostatic and analgenic medication in tonsillectomy. Vestnik otorinolaringologii. 2007; 48-50.

37. Sánchez M, Guadilla J, Fiz N, Andia I. Ultrasound-guided platelet-rich plasma injections for the treatment of osteoarthritis of the hip. Rheumatology. 2012;51(1):144-50.

38. Luo $H$, Zhang $Y$, Zhang $Z$, Jin $Y$. The protection of MSCs from apoptosis in nerve regeneration by TGF $\beta 1$ through reducing inflammation and promoting VEGF-dependent angiogenesis. Biomaterials. 2012;33:4277-87.

39. Rao SN, Pearse DD. Regulating axonal responses to injury: the intersection between signaling pathways involved in axon myelination and the inhibition of axon regeneration. Front Mol Neurosci. 2016;9:33.

40. Allampallam $\mathrm{K}$, Chakraborty J, Robinson J. Effect of ascorbic acid and growth factors on collagen metabolism of flexor retinaculum cells from individuals with and without carpal tunnel syndrome. J Occup Environ Med. 2000;42(3):251-9.

41. Cho HH, Jang S, Lee SC, Jeong HS, Park JS, Han JY, et al. Effect of neural-induced mesenchymal stem cells and platelet-rich plasma on facial nerve regeneration in an acute nerve injury model. Laryngoscope. 2010;120(5):907-13.

42. Wang $X$, Luo E, Li Y, Hu J. Schwann-like mesenchymal stem cells within vein graft facilitate facial nerve regeneration and remyelination. Brain Res. 2011; 1383:71-80

43. Wang Y, Jia H, Li WY, Tong XJ, Liu GB, Kang SW. Synergistic effects of bone mesenchymal stem cells and chondroitinase $A B C$ on nerve regeneration after acellular nerve allograft in rats. Cell Mol Neurobiol. 2012;32:361-71.

44. Yu W, Wang J, Yin J. Platelet-rich plasma: a promising product for treatment of peripheral nerve regeneration after nerve injury. Int J Neurosci. 2011; 121(4):176-80

45. Piñeros-Fernández A, Rodeheaver PF, Rodeheaver GT. Octyl 2-cyanoacrylate for repair of peripheral nerve. Ann Plast Surg. 2005;55(2):188-95.

46. Dugrillon A, Eichler H, Kern S, Kluter H. Autologous concentrated plateletrich plasma (CPRP) for local application in bone regeneration. Int J Oral Maxillofac Surg. 2002;31:615-9.

47. Bausset O, Giraudo L, Veran J, Magalon J, Coudreuse JM, Magalon G, et al. Formulation and storage of platelet-rich plasma homemade product. Biores Open Access. 2012;1(3):115-23.

48. Weibrich G, Kleis WKG, Hafner G. Growth factor levels in the platelet-rich plasma produced by 2 different methods: curasan-type PRP kit versus PCCS PRP system. Int J Oral Maxillofac Implants. 2002;17(2):184-90.

49. Schmitz G, Rothe G, Ruf A, Barlage S, Tschöpe D, Clemetson K, et al. European Working Group on clinical cell analysis: consensus protocol for the flow cytometric characterization of platelet function. Thromb Haemost. 1998;79:885-96.

50. Efeoglu C, Akcay YD, Erturk S. A modified method for preparing platelet-rich plasma: an experimental study. J Oral Maxillofac Surg. 2004;62:1403-7.

51. Tamimi FM, Montalvo S, Tresguerres I, Blanco JL. A comparative study of 2 methods for obtaining platelet-rich plasma. J Oral Maxillofac Surg. 2007;65: 1084-93.

\section{Publisher's Note}

Springer Nature remains neutral with regard to jurisdictional claims in published maps and institutional affiliations.

\section{Submit your manuscript to a SpringerOpen ${ }^{\circ}$ journal and benefit from:}

- Convenient online submission

- Rigorous peer review

- Open access: articles freely available online

- High visibility within the field

- Retaining the copyright to your article

Submit your next manuscript at $\boldsymbol{\nabla}$ springeropen.com 